\title{
From the lab to the poll: The use of survey experiments in political research
}

\author{
Sergio Martini (D) and Francesco Olmastroni* (D) \\ Department of Social Political and Cognitive Sciences, University of Siena, Siena, Italy \\ *Corresponding author. Email: olmastroni3@unisi.it
}

(Received 15 July 2020; revised 24 April 2021; accepted 29 April 2021; first published online 28 May 2021)

\begin{abstract}
The article offers an overview of the use of survey experiments in political research by relying on available examples, bibliographic data and a content analysis of experimental manuscripts published in leading academic journals over the last two decades. After a short primer to the experimental approach, we discuss the development, applications and potential problems to internal and external validity in survey experimentation. The article also provides original examples, contrasting a traditional factorial and a more innovative conjoint design, to show how survey experiments can be used to test theory on relevant political topics. The main challenges and possibilities encountered in envisaging, planning and implementing survey experiments are examined. The article outlines the merits, limits and implications of the use of the experimental method in political research.
\end{abstract}

Key words: Asylum seeking; candidate preference; causal inference; conjoint analysis; experimental method; factorial survey; randomisation; survey experiments

\section{Introduction}

Randomised-controlled experiments represent the gold standard for ascertaining causation. This is not to say that experiments are free of limitations and, as will be clarified, some of them contributed to a certain reluctance towards the usage of experimental methods in political science. While acknowledging the merit of experimentation in the empirical investigation of causal claims, political scientists long lagged behind psychologists and economists in the use of the experimental approach. It was only with the development of (population-based) survey experiments, facilitated by new advancements in survey techniques, that some of these limitations, and in particular the scarce generalisability of the results from an experimental sample to a population of interest, were mitigated, unveiling the virtues of the experimental design to a wider audience of social and political scientists.

This article provides an overview of the use of survey experiments in political research and an illustration of how experimental data can be modelled and interpreted. Then, it describes some key concepts for the understanding and application of experiments in the discipline, clarifying the basic theoretical issues tied to causal inference and the most common experimental designs to achieve it. In the following section, we focus on survey experiments and their ambition to combine internal and external validity. By presenting the results of a content analysis of experimental articles published by leading academic journals over the last two decades, we show a lag in the use of experimentation in European research as compared to the American one, but also an increasing interest in survey experiments from European scholars. Based on this and with the purpose of

(C) Società Italiana di Scienza Politica 2021. This is an Open Access article, distributed under the terms of the Creative Commons AttributionNonCommercial-NoDerivatives licence (http://creativecommons.org/licenses/by-nc-nd/4.0/), which permits non-commercial re-use, distribution, and reproduction in any medium, provided the original work is unaltered and is properly cited. The written permission of Cambridge University Press must be obtained for commercial re-use or in order to create a derivative work. 
introducing the main challenges and possibilities encountered in designing, planning and implementing survey experiments, we then contrast a traditional factorial and a more innovative conjoint design, considering how treatments are usually formulated and assigned. In this regard, we illustrate how survey experimental data can be analysed to estimate average treatment effects and conditional treatment effects across subgroups of subjects by means of two original examples on attitudes towards asylum seekers and preference towards political candidates, respectively. We conclude with some considerations on the merits, limits and implications of experimental designs in political research.

\section{A primer to experiments}

Green (2004) points to two main characteristics to distinguish the experimental design from other methods of social investigation: a planned intervention and a random assignment. The first refers to the treatment administered to the units of analysis and whose impact on the outcome variable the researcher is interested to estimate. The treatment represents the independent variable and, in controlled experiments, is manipulated under the direct control of the researcher. The second characteristic, instead, has to do with the process through which subjects are allocated to one (or more) treatment group(s). Randomisation ensures that all groups are balanced across potential covariates - an assumption that the experimental analyst should nonetheless demonstrate - and that no systemic relationships exist between the treatment factor(s) and other observed or unobserved variables.

Because of these two key features, experimental studies are considered to be better equipped to address causal questions than observational studies. Contrary to observational research, where the researcher usually relies on statistical modelling to avoid problems of endogeneity and unobserved heterogeneity, in an experimental setting confounding variables are controlled by design, resulting in unbiased causal inference if randomisation has been properly implemented. Since in an experimental study each subject has the same probability to be assigned to a treatment condition, the final outcome will solely depend on the stimulus received, while the effect of possible confounding factors will be balanced across all the considered groups. ${ }^{1}$

Experiments usually achieve superior internal validity - the possibility of establishing a causal effect (McDermott, 2011) - through a 'between-subject' design in which the subject is assigned either to a treatment condition (i.e., the one that receives the intended manipulation) or to a control condition (i.e., the one that is used as a counterfactual to estimate what would have happened if the intervention had not been administered).

However, experiments also allow to vary treatments while holding subjects constant and controlling for subject-specific effects. This is the case of 'within-subject' designs, in which each participant receives one or more treatments (or controls) and causal estimates are obtained by comparing the same subjects' behaviour across the different conditions over the experiment duration, generally before and after each treatment. Within-subject designs, which require independence of exposure to multiple treatments, have greater statistical power than between-subject designs, as more data points are offered for the same subjects. Moreover, they are more adequate in environments where an individual faces more than one choice during a sequence of events (e.g., as in bargaining and collective action research). Still, 'within-subject' designs may introduce possible confounds by exposing the same subject to multiple interventions and more likely produce spurious results due to a 'demand effect', i.e., participants understand the experimenter's intention and behave accordingly to satisfy her or his expectations (Charness et al., 2012).

\footnotetext{
${ }^{1}$ This way, experiments address the three requirements for causal inference: (1) identifying a statistically significant association between two conditions; (2) establishing a precise temporal order between cause and effect; (3) avoiding the observed relationship to be confounded by third variables (Mutz 2011). On the potential outcome approach and the Neyman-Rubin casual model, see Druckman et al. (2011).
} 
The standard procedure to estimate the treatment effect is to compare the differences for the outcome of interest across the different groups or experimental conditions, also known as the average treatment effect (ATE). However, experimenters may also decide to test for possible moderators and baseline covariates that might affect the relationship between the treatment and the outcome, thus assessing possible heterogeneity of a treatment effect depending on another treatment or one or more characteristics of the participants. This is commonly done using a regression model with interaction terms (moderators) to estimate the conditional average treatment effect (CATE).

Across disciplines, experiments have been more concerned with the identification of treatment effects than the generalisability of findings across different subjects and groups - the external validity (McDermott, 2011). This is specifically the case of 'laboratory' experiments, which generally occur in a more artificial but highly controlled environment. Laboratory experiments have the advantage of flexibility, as they can easily be conducted at low costs with convenience samples, including students and volunteers. However, participants in such experiments are generally viewed as unrepresentative of any target population (Iyengar, 2011). Moreover, laboratory experiments imply some sort of interaction between participants and researchers, so that results may be biased by demand effects (Zizzo, 2010). Last, in spite of better control, the artificial nature of the setting may prevent results to be extended to real-world situations. It is worth mentioning, however, that this kind of experiments can be moved from a typical university laboratory to a more naturalistic one (township, households), so to have a hybrid 'lab-in-the-field' design (Morton and Williams, 2010).

When treatments are randomly administered in a naturalistic setting under the direct control of the researcher, these are classified as 'field' experiments. By evaluating the effect of the treatment in a real-world setting, the analyst has the possibility to make unbiased and externally valid causal claims. One can argue that estimates derived from one setting at a given time cannot be applied easily to another context or time period. Still, as Green and Gerber (2003: 101) pointed out, 'extrapolation from one field setting to another involves less uncertainty than the jump from lab to field or from non-experimental correlations to causation'. When researchers take advantage of random assignments that occur naturally but not under their direct planned intervention (e.g., use of a lottery to allocate resources, policies or duties), instead, we are in the presence of a randomised 'natural' experiment (Dunning, 2012). ${ }^{2}$

Last, experiments may be embedded in a survey through the manipulation of different elements of a questionnaire (Gaines et al., 2007). These experimental settings combine treatment manipulation and random assignment with survey sampling, ensuring a broader variation of the pool of subjects being considered and helping bring experimental research outside of the lab. Survey experiments may be conducted with either non-probability or probability samples of participants; when administered to a randomly selected, representative sample of a target population, they are referred to as 'population-based survey experiments' (henceforth PBSE) and allow the researcher to make population inferences about causal relationships drawn from experimental findings (Mutz, 2011).

\section{Survey experiments in political research Development of survey experiments}

Experiments for long remained an almost uncharted territory for political scientists, given their interest in the generalisability of findings to target populations, the asserted artificiality of the laboratory setting and unrepresentativeness of the experimental subjects (Iyengar, 2011). It was only in the 1970s, with the emergence of political psychology as an interdisciplinary field, that a certain interest in the experimental approach started to develop (McGraw and Hoekstra, 1994).

\footnotetext{
${ }^{2}$ Trials in which units are not randomly assigned, but where the 'researcher can credibly claim that treatment is as good as randomized' (Dunning, 2012: 16), are referred as 'as-if randomised natural experiments. These quasi-natural designs are not usually considered 'true' experiments (Druckman et al., 2006).
} 
Nevertheless, we had to wait until the 1990s to observe a real growth in the number of experimental studies in political science, especially in the US. As Druckman and colleagues have reported, more than half of the experimental articles appeared in the American Political Science Review (henceforth APSR) between its foundation in 1906 and the late 2000s was published after 1992 (Druckman et al., 2006, 2011). Political scientists' increasing reliance on experimental methods was later confirmed by Dunning and Rosenblatt (2016), who found a further increase in the number of APSR articles reporting experimental research in the early 2010s. This was the result of technological improvement connected to computer assisted telephone interview as well as ambitious projects, such as the Multi-Investigator Study and the following Time-Sharing Experiments for the Social Sciences, which allowed researchers to administer complex randomised experiments to large probability samples of participants (Sniderman and Grob, 1996; Mutz 2011).

Building on Druckman and colleagues' criteria to classify research articles presenting 'primary data from a random assignment study with participants' (Druckman et al., 2006: 628-629), we can observe a remarkable increase $(33.3 \%)$ in the number of APSR articles using randomised experiments in the last five years as compared to the 2010-2014 period (Figure 1), with a peak between 2018 and $2019(N=21)$. Indeed, the percentage of experimental manuscripts over the total number of articles published in an issue of this journal has gradually grown over the last 15 years, so that experimental articles accounted for about one-fifth of APSR manuscripts in $2019 .^{3}$

A similar upward trend, albeit of different magnitude, is observed in European political research. Using the European Journal of Political Research (henceforth EJPR) as a benchmark to assess whether and to what extent experimentation has also gained acceptance in Europe, ${ }^{4}$ we found that about two-thirds $(63 \%)$ of the articles making use of randomised experiments between 2000 and 2019 have been published in the last four years. The volume of experimental manuscripts, however, has remained quite low if compared with APSR. Experimental articles, on average, still account for only $5.1 \%$ of total manuscripts published each year by EJPR, signalling that the use of experimental methods is not only relatively newer to European scholars but also less prominent than in the American context.

European political scientists' hesitation with the use of experimental methods is also confirmed by a content analysis of the manuscripts. While the typology of experiments in APSR articles is quite various, with more than one-third of the cases (37.6\%) making use of a survey experiment, followed by laboratory (32.3\%), field (30.1\%) and natural experiments (3.2\%), almost the totality of EJPR experimental articles (93.8\%) relied on survey experiments. Only in a few instances field (12.5\%) and laboratory experiments (6.3\%) appeared in the journal, whereas natural experiments have not been published in a volume of EJPR over the last two decades. Yet, these figures also highlight a large interest towards survey experiments and their primacy over other type of settings. In this respect, it is interesting to note that PBSE account for $62.9 \%$ and $40 \%$ of APSR and EJPR survey experiments published in the 2000-2019 period, respectively.

\section{Survey experiments in practice: vignette factorial and conjoint designs}

Initially, the use of survey experiments was mostly limited to address measurement issues through the manipulation of the presence, wording or order of questionnaire items and their random allocation to interviewees. In one of the earliest examples of the 'split ballot' experiment, for instance,

\footnotetext{
${ }^{3}$ For further details on the criteria to select published manuscripts, see Appendix A.

${ }^{4}$ Similarly to what Druckman et al. $(2006,2011)$ did for the American case, we selected the official, longest-running publication of the leading scholarly society for political scientists in Europe (European Consortium for Political Research) under the assumption that if experiments are being published in EJPR, experimental methods are also being accepted by other specialty journals; see McGraw and Hoekstra (1994) on this point.
} 


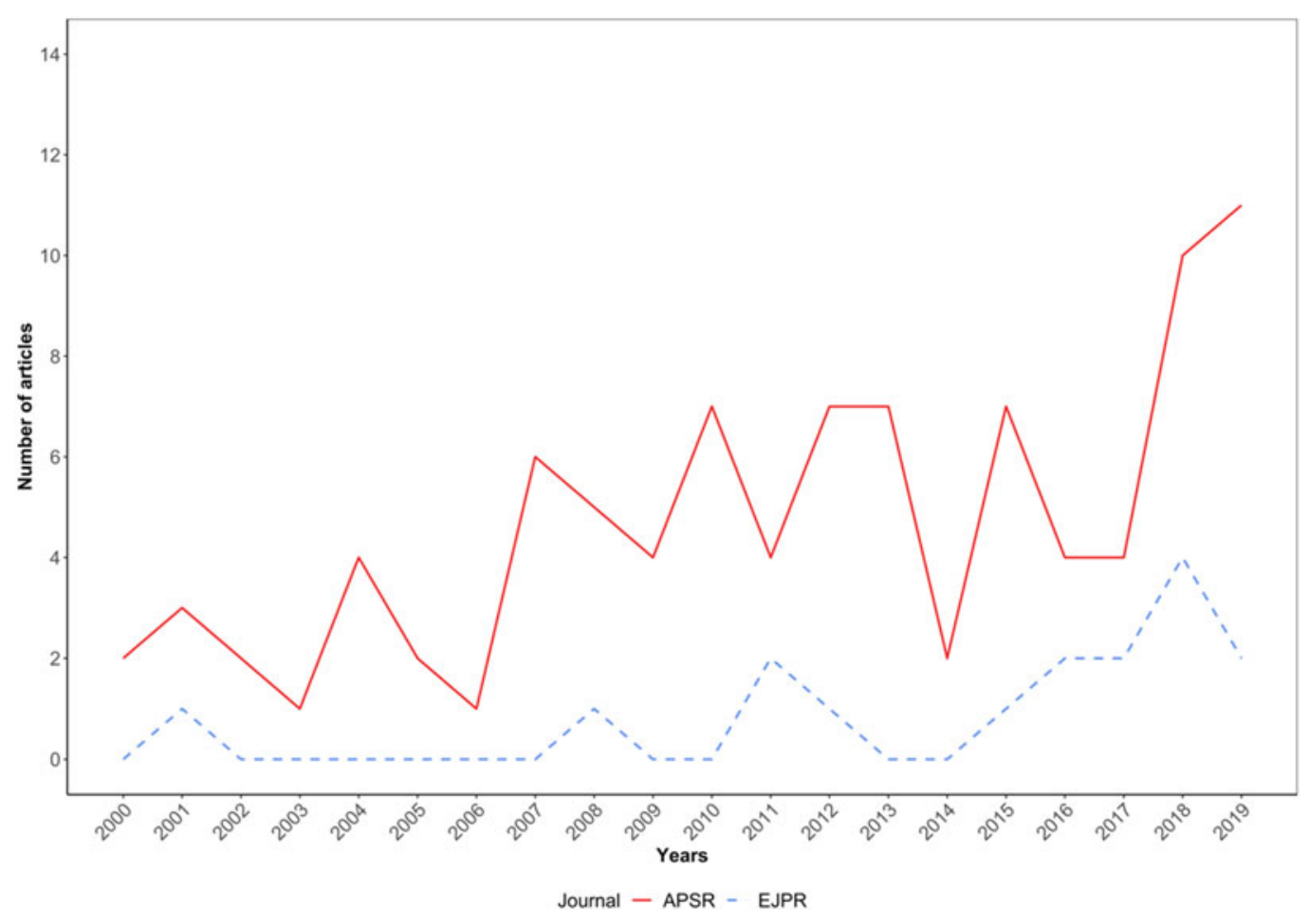

Figure 1. Number of experimental articles in APSR and EJPR, 2000-2019.

Rugg (1941) found that Americans were more likely to support freedom of speech against democracy when asked whether the US should 'forbid' ( $46 \%$ of the interviewees answered 'yes') rather than 'allow' (62\% of the sample answered 'no') public speeches against democracy. Over the years, survey experiments based on question wording have then been employed to address more substantive issues, testing, for instance, how framing may affect citizens' opinions about public policies (e.g., Kinder and Sanders, 1996).

However, the most common paradigm to formulate treatments has been the use of vignettes, in which a short text describes a situation, a policy proposal or a political stance often in combination with pictures and/or videos. Vignette experiments are very well-suited to determine the extent to which multiple factors contribute to attitude formation or the occurring of certain behaviours. Overcoming the main weakness of the simple 'split ballot', in which levels (values) of different factors (attributes) may vary only one at a time, 'vignette factorial designs' allow to estimate the joint effect of multiple attributes at their different levels (Mutz, 2011), with the number of treatment groups being determined by the number of combinations of factor levels.

The first advantage of this design is that factors are randomly assigned and orthogonal to each other, thus allowing a researcher to estimate the effect of each single treatment while ignoring the others if these are shown to be insignificant. Otherwise, s/he needs to take into account that the average effect of one factor is weighted across the levels of the others (Gerber and Green, 2012). Second, factorial designs can be used to estimate not only how two or more treatments interact among them, but also the extent to which a given factor (or the combination of some factors) hinges on a third characteristic of the respondent, which is uncorrelated by randomisation. In this respect, a 'full factorial design', in which all the combinations of the factor levels are examined, has to be distinguished from a 'fractional factorial design', in which only a subset of these combinations is considered either because their number is too large or because resources for 
testing them all are not available. This last consideration leads us to one of the disadvantages of factorial designs, which is the trade-off between the number of conditions to be considered and the sample size. Researchers may increase the number of experimental factors only at the cost of efficiency. The number of conditions has, in fact, to be taken into account in relation with the number of subjects per experimental group and statistical power, that is, the probability of being able to reject the null hypothesis of no treatment effect (Gerber and Green, 2012).

Such a disadvantage can be avoided in 'conjoint analysis', a prime technique of preference elicitation introduced at the beginning of the 1980s (Alves and Rossi, 1978) and commonly used in marketing research, whose recent formalisation by Hainmueller et al. (2013) has contributed to its popularity among political scientists. In conjoint experiments, respondents are requested to choose (discrete-choice conjoint analysis) and/or to rate (rating-based conjoint analysis) sets of possible alternatives (e.g., candidates to vote for, policy proposal to pass) resulting from the random variation of an indefinite number of factors, orthogonal among each other, that can assume multiple values. The analysis consists of estimating the simultaneous independent causal effects - average marginal component effect (AMCE) - of many features of multidimensional objects on the respondent's decision.

Contrary to common survey research, conjoint analysis starts from the assumption that social and political phenomena come in different facets that individuals are likely to simultaneously evaluate in real-world situations. Asking the respondent to judge a given object by introducing trade-off costs among different aspects helps reduce the problem of social desirability and the artificiality of the task while increasing the level of external validity (Hainmueller et al., 2015).

Conjoint experiments are not exempt from criticism. First, they are cognitively demanding, as conducting such complex experiments with many attributes evaluated at once requires the repetition of the designed task. In this respect, there is no agreement on the ideal number of attributes to consider, nor on the number of tasks to be implemented. Researchers need to balance among the theoretical aspects to investigate, the respondents' fatigue, as well as sample size and statistical power (Bansak et al., 2018, 2021). A second criticism is that conjoint analysis may lead scholars to less formalised and more inductive forms of research, posing less restrictions with respect to the number of factors under observation. As some have argued (e.g., Sniderman 2018), however, this would represent more a pro than a con, since the whole scope of conducting an experiment is actually to evaluate countervailing explanations.

Remarkably, more than one-third of survey experiments appeared in APSR (5 out of 14) and EJPR ( 3 out of 10) between 2015 and 2019 were based on a conjoint approach, with the remaining two-thirds largely relying on a traditional factorial design. Given the widespread use of these two techniques in contemporary political research and in order to offer a valuable help to scholars interested in modelling this kind of data, in the next section we present the experimental protocol and results of a full factorial experiment on respondents' evaluation of asylum applications, moving then to a conjoint experiment on preferences towards ideal political candidates. First, however, we describe some problems to internal and external validity a researcher may face when conducting survey experiments. These problems will then be addressed in the analyses of our case studies.

\section{Potential problems in survey experiments}

When conducting survey experiments researchers need to address some challenges. One of the most relevant has to do with 'noncompliance' and its impact on internal validity (Druckman et al., 2011). This problem occurs when the subjects assigned to a certain treatment (including control) do not receive it. This might take place as a result of either the respondent's active behaviour (e.g., not accomplishing a given task or dropping out during the survey) or an involuntary action (e.g., the participant receives a different treatment from that to which s/he was assigned or eventually s/he is not exposed to any stimulus). 
To tackle active noncompliance, a researcher may evaluate participants' level of attention via the recorded duration of the experiment or the use of screening questions posed during the interview and asking respondents to select a certain response option to check for their cooperation (Berinsky et al., 2014). Lower attention, however, does not necessarily imply no treatment. An alternative to address this problem is to include 'manipulation checks', that is, additional questions placed at the end of the experiment to evaluate whether or not the subject received the treatment as intended. Overall, there is still a debate on the utility of these types of questions since the post-treatment exclusion of subjects with low levels of attention or failing to pass manipulation checks may add a bias rather than help the analyst establish the treatment's causal effect (Gerber et al., 2014; Mutz and Pemantle, 2015).

When noncompliance is passive and related to failure in random assignment, the researcher should carefully discuss the number of subjects initially eligible for the study, the size of groups assigned to a certain treatment, how many did not receive the planned intervention, how the statistical analysis was handled and if any subject was excluded after the experiment. Ideally, researchers should provide intent-to-treat analysis of outcome variables considering all subjects assigned to a group regardless of whether the treatment was assigned or not (Gerber et al., 2014).

Another important challenge to internal validity has to do with 'treatment spill-over effects' (Transue et al., 2009), namely the possible contamination between treatments pertaining to different experiments included in the same survey. Given the greater complexity of modern surveys, it is always a good practice to randomise the order of experiments (if more than one is included) and evaluate a possible order effect when analysing data.

Turning to external validity, the first challenge deals with 'sampling issues'. Available studies have not detected significant differences between experimental treatment effects (both ATE and CATE) obtained through non-probabilistic and representative population samples (e.g., Mullinix et al., 2015; Coppock et al., 2018). Still, it should be emphasised that PBSE are one of the most effective tools to combine causal inference and external validity. In this case, it is always recommended to report sample characteristics (Gerber et al., 2014) and, if applied, the employed weighting scheme.

Ultimately, external validity has also to do with the extent to which outcomes observed in an experiment resemble real-world situations. One common criticism raised towards laboratory and survey experiments concerns the lack of realism as they offer a stylised setting and treatments that are often deemed to mirror complex everyday situations only imperfectly (Sniderman, 2018). In a survey context, moreover, the stimuli might be more easily received than in the real world where competing frames are present (Barabas and Jerit, 2010). Thus, researchers should provide a justification of the stimuli and settings used in the experiment and carefully evaluate the results. Eventually, they might also try to validate them with similar situations in real-world environments (Hainmueller et al., 2015). That said, and although not being exempt from limitations, survey experiments represent a useful tool to test theories about a broad range of political phenomena. As in the case of any other research endeavour, drafting, conducting and analysing an experiment is a difficult task of which each step should be discussed in detail and in accordance with shared standards (Gerber et al., 2014; Mutz and Pemantle, 2015).

\section{A factorial experiment on preferences towards asylum seekers}

Following the so-called refugee crisis, the issue of immigration has become increasingly relevant in Europe, contributing to the development of a climate of insecurity and cultural threat among the European publics (Basile and Olmastroni, 2020). Given its proximity to the Libyan coasts, the crisis has been even harsher in Italy. In the last few years, anti-immigrant sentiments have spread among citizens, with populist and right-wing parties often resorting to anti-Muslim rhetoric and capitalising on people's resentment (Guidi and Martini, 2019).

Yet, while Western citizens may tend to oppose more open immigration policies, some experimental studies show that they are far less reluctant to admit individual immigrants. This person- 
positivity bias seems to vary according to the immigrant's profile, with preferences over asylumseekers structured by economic, humanitarian and ethnic concerns. Specifically, asylum seekers with a high-skill background (i.e., a better occupational standing) are more likely to be accepted than those with low-skill profiles (Iyengar et al., 2013). Immigrants who fear political prosecution are more likely to be favoured than those who move for economic reasons (Bansak et al., 2016), whereas individuals from Muslim-majority countries would have less chances to see their asylum request accepted (Valentino et al., 2019). Interestingly, leftists seem to be more sensitive to humanitarian vis-à-vis instrumental reasons and less concerned about immigrants' religious identity than their right-wing fellow citizens (Bansak et al., 2016). Coming to the Italian context, experiments covering this topic are rare, with exceptions showing a link between ideology and party alignments, on the one hand, and partisan cue-taking and ethnic prejudice, on the other (Barisione, 2020).

Thus, one factorial experiment might help disentangle what factors matter the most for asylum-seeker acceptance, whether there is an interplay among instrumental, humanitarian and ethnic considerations, and to what extent, if any, political ideology moderates their relationships. Although the following example is merely illustrative, available research (Bansak et al., 2016; Barisione, 2020) leads us to believe that Italians would look more favourably at asylum applications pursued by skilled immigrants rather than low-skilled ones (h1); by those escaping war as compared to those coming for economic opportunities (h2); or by subjects from Christian-majority countries against Muslim-majority ones (h3).

We also can assume that the applicant's skills and ethnicity might moderate the differential effect of the motivation for migrating, so that the gap in the approval of an asylum application presented by an individual escaping from war and one looking for better economic conditions would be reduced when the subject is skilled and from a Christian-majority country (h4).

Last, we might expect instrumental, humanitarian and ethnic concerns to hinge on the ideology of the respondent, such that the approval gap between skilled and non-skilled migrants will be larger among right-wing participants than among left-wing ones (h5a); the approval gap between migrants coming for economic and humanitarian reasons will be smaller among right-wing voters compared to left-wing ones (h5b); and the approval gap between migrants coming from Christian-majority vis-à-vis Muslim-majority countries will be larger among right-wing respondents compared to left-wing ones (h5c).

\section{Data}

The experiment we consider in this section was embedded in the second wave of the EUENGAGE online panel survey, conducted between 6 July and 6 October 2017. Respondents were approached through an opt-in online panel provided by Research Now using quota sampling to reflect the general population's characteristics (see Appendix A). While the whole sample includes individuals from $10 \mathrm{EU}$ member states, our analysis is limited to the Italian sample $(n=1278)$. Since weighting non-probability samples may be a problematic task (Mullinix et al., 2015), we decided to present analysis on unweighted data, thus focusing on causal relationships without any claim of representativeness or generalisability.

\section{Vignette}

Respondents began the experiment by reading a short introduction about an asylum applicant interested in migrating to Italy. Then, each interviewee was invited to examine his background along with a picture of the applicant. While the picture remained constant, subjects were randomly assigned to one of the eight different experimental groups resulting from the combination of three treatments. Figure 2 shows one possible vignette generated through the random assignment of the examined conditions (the full protocol is in Appendix B). 
Let's talk now about an individual who is interested in migrating to Italy.

Please, take a minute and read about his background.

He is a Syrian man, skilled, fleeing from war.

Given what you know about this potential immigrant, do you think his application for asylum should be approved or rejected?

Figure 2. Stimuli: an illustration of the factorial experiment.

The picture comes from the Chicago Face Database (Ma et al., 2015), a free source of highresolution pictures standardised and validated via subjective evaluations and objective physical measurements. In our case, the results of subjective ratings classify the picture as a man, rated between Latino and white ethnic origin, aged around 43 years, with a neutral expression. The use of a fixed picture contributed to increase the credibility of the task while holding a broad range of conditions (gender, age and emotional facial expressions) constant across all respondents.

The experiment manipulated three conditions, providing us with a $2 \times 2 \times 2$ full factorial design in which each hypothetical scenario presented the respondents with varying information about the migrant's qualification (low skilled or skilled), the reasons for leaving his country (looking for job or fleeing from war) and his ethnic origins (Syrian or Ukrainian). Differently from Iyengar et al. (2013) and Valentino et al. (2019), the vignette did not specify what types of skills the applicant had, while it introduced the reason for migrating. When it comes to the country of origin, the vignette included two ethnic groups among which we might have asylum applicants, Syria and Ukraine being two contexts of conflict at the time of fieldwork. Moreover, the former constitutes a Muslim-majority country while the latter a Christian-majority one. Last, Ukrainians are a more familiar type of foreign immigrants in Italy, being the 5th most represented group out of 169 nationalities present in the country, than Syrians, who rank 69th (ISTAT 2017). This should elicit different degrees of cultural contrast between the two groups (higher for Syrians and lower for Ukrainians). Table 1 summarises all the experimental conditions and lists the number of respondents assigned to each group. Finally, after reading the scenario, the respondents had to express whether the migrant's application for asylum ought to be approved or rejected, so answers were collected in a dichotomous format, mimicking a real-world choice by a public official.

To check for the robustness of the random assignment, we performed balance tests by multinomial regression, regressing assignment to a certain experimental group on a set of sociodemographic characteristics (gender, age, educational attainment). Moreover, since our experiment involves the respondents' reaction to the admission of asylum seekers, we also checked for balance in ideology, party identity and attitudes towards immigration. The results confirm that the random procedure was correct with no variable being statistically different across the treatment groups (see Appendix C). Hence, any difference between conditions should be attributed to treatment manipulation only and not to other confounding factors.

It has to be noticed that this was not the only experiment included in the survey. In fact, other two experiments on the topics of the economy and globalisation were present, implying potential spill-overs among the three. However, the experiments were presented in a randomised order, a procedure that, as discussed above, can alleviate this type of bias. 
Table 1. Randomly assigned conditions in the factorial experiment

\begin{tabular}{|c|c|c|c|c|}
\hline \multirow[b]{2}{*}{ Experimental group } & \multicolumn{4}{|c|}{ Treatment } \\
\hline & qualification (T1) & Reason for leaving the country (T2) & Origin (T3) & $N$ \\
\hline G1 & Skilled & Fleeing from war & Syrian & 164 \\
\hline $\mathrm{G} 2$ & Skilled & Looking for a job & Syrian & 155 \\
\hline G3 & Low skilled & Fleeing from war & Syrian & 154 \\
\hline G4 & Low skilled & Looking for a job & Syrian & 152 \\
\hline G5 & Skilled & Fleeing from war & Ukrainian & 157 \\
\hline G6 & Skilled & Looking for a job & Ukrainian & 155 \\
\hline G7 & Low skilled & Fleeing from war & Ukrainian & 151 \\
\hline G8 & Low skilled & Looking for a job & Ukrainian & 125 \\
\hline
\end{tabular}

\section{Empirical analysis}

To begin, it is worth mentioning that the general approval rate of the proposed asylum application is fairly high, with around $63 \%$ of respondents willing to accept the assigned request. This result aligns with studies conducted in other countries (Iyengar et al., 2013; Valentino et al., 2019), though we take it with caution since it comes from a non-representative sample.

Given that our dependent variable is dichotomous in format, we estimated a logistic regression model. By reason of the experimental setting, we do not need to build a complex model with a battery of control variables. Rather, we identify the effects of our treatments by plugging dummy variables in as well as their interactions. For the sake of simplicity, we display results showing predicted probabilities of approval of asylum applications as a function of our covariates. To get the ATEs, we computed average marginal effects and performed Wald tests (formal notations and full models are reported in Appendix D).

We start by considering the main effect of our three treatments as they stand alone. It should be noted that approval clearly depends on profile features, confirming our first expectation (h1). Specifically, skilled applicants have $18 \%$ more probability to get accepted than non-skilled applicants $\left(\chi^{2}=45.45 ; P<0.001\right)$. Similarly, people fleeing from war have $17 \%$ more probability to see their application approved than individuals coming to Italy to find a job, thus corroborating our second anticipation (h2) $\left(\chi^{2}=43.37 ; P<0.001\right)$. Last, contrary to our third expectation (h3), a Syrian applicant has higher chances to be granted asylum, though the difference is small and nonsignificant ( $5 \%$ difference; $\chi^{2}=3.38 ; P=0.065$ ) (for a graphical representation, see Appendix $\mathrm{D}$ ).

However, each of these values constitutes the effect of a single treatment on the dependent variable averaged across the levels of the other experimental conditions. The second step of our analysis is to explore the interplay among our three independent variables. The idea, here, is to test whether the gap in the approval rate between applicants escaping from war and those looking for better economic conditions is reduced when the applicant is skilled and from a Christian-majority country. Figure 3 shows the results of our model plotting the effects of two conditions - the level of qualification and the reason for leaving the country - and split them into two panels, depending on whether the potential refugee is from Syria (left panel) or from Ukraine (right panel).

In the case of a Syrian applicant, we do not find a statistically significant interaction effect between skills and motivation for migrating. A detailed examination of the predicted probabilities from the combination of treatment conditions reveals that approval rates are always higher when the applicant has a humanitarian reason for requesting asylum (fleeing from war) compared to those who come for economic opportunities (looking for job). This is so for an unskilled applicant escaping from a war context, who has 20 percentage points $\left(\chi^{2}=14.20 ; P<0.001\right)$ more probability to get a final approval than a similar unskilled applicant looking for a new job position. Similarly, skilled applicants fleeing from a conflict have more chances of being approved 


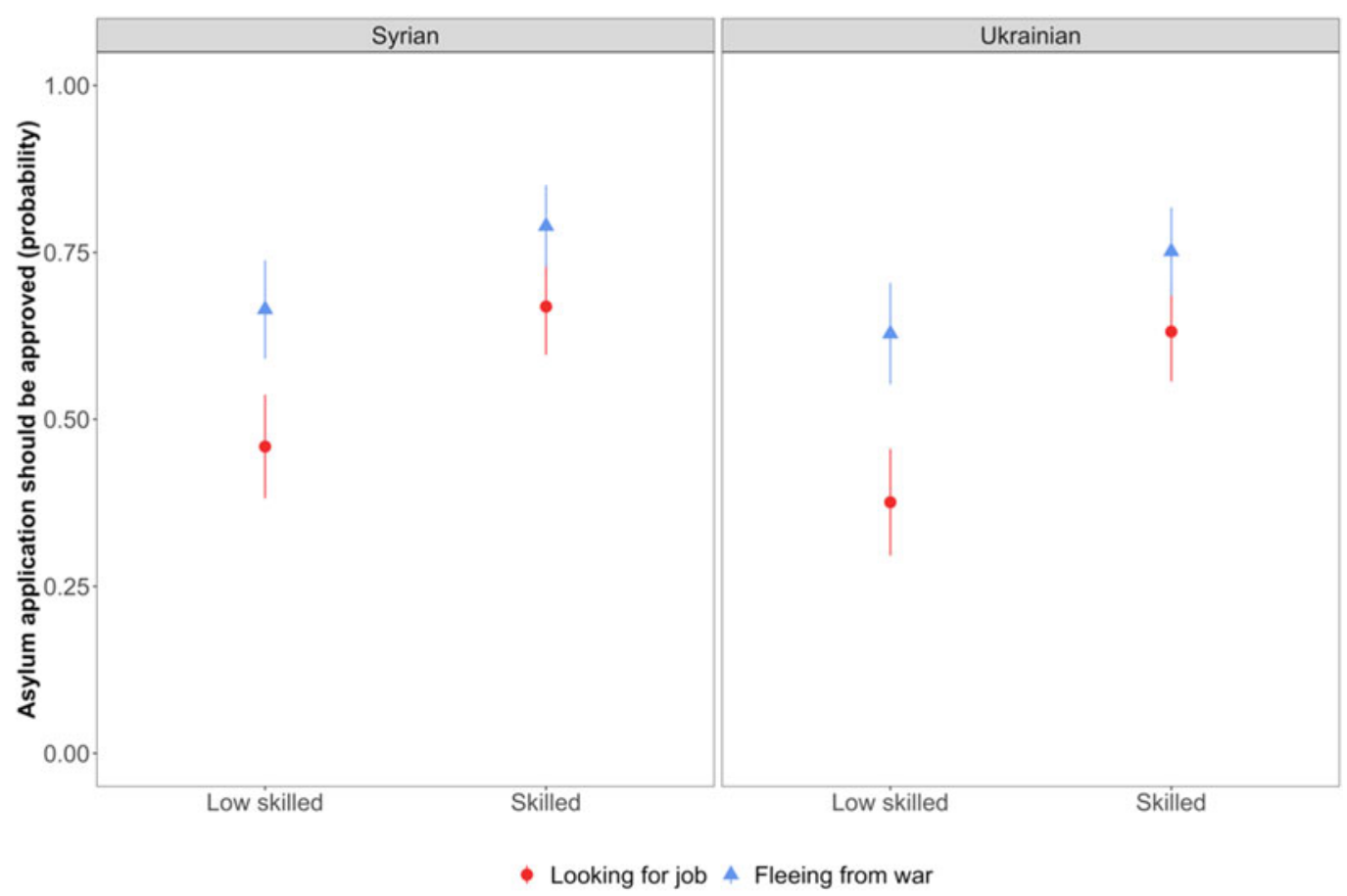

Figure 3. The effect of skills and reasons for leaving the country on the probability to accept asylum applications by immigrant's ethnic group.

Note: Graph shows predicted probabilities based on logit regression. Lines on both sides of the points represent $95 \%$ confidence intervals.

than skilled individuals who are job seeking ( $12 \%$ difference; $\left.\chi^{2}=6.26 ; P<0.05\right)$. Moreover, if we keep the reason of moving for economic opportunities as a reference and compare low skilled and skilled individuals, this increases the probability of the latter of being accepted $(21 \%$ higher for skilled refugees; $\chi^{2}=15.04 ; P<0.001$ ); yet, not enough to close the gap with skilled subjects coming for political reasons.

Turning to the case of an Ukrainian applicant, we find the same pattern, meaning that we do not find an interaction between qualification and reason for leaving the country, a result that also extends to the ethnic origins. ${ }^{5}$ Shortly, in contrast with our fourth expectation (h4), we might say that skills temper the effect of migrating for economic opportunities; however, this effect is not strong enough to significantly reduce the gap in the acceptance rate of skilled applicants moving for humanitarian reasons.

We conclude by examining whether the effects of the applicant's skills, reason for migrating and ethnicity are moderated by the ideology of the respondent. Figure 4 displays the results of a two-way interaction model between our treatments and the ideological positioning of the respondent. As we can see, although left-wing participants tend to express higher levels of approval than right-wing respondents, we do not find different patterns for ideology. In fact, when the applicant is either skilled or migrates for humanitarian reasons, approval rates improve to the same degree across ideological groups, so we do not detect any larger or smaller gap in these conditions depending on ideology, rejecting our expectations (h5a, h5b). When it comes

\footnotetext{
${ }^{5}$ For the right-hand panel (Ukrainian), the differences are: unskilled looking for job vs. fleeing from war $=25 \%\left(\chi^{2}=20.14\right.$; $P<0.001)$; skilled looking for job vs. fleeing from war $=12 \%\left(\chi^{2}=5.59 ; P<0.05\right)$; unskilled looking for job vs. skilled looking for job $=26 \%\left(\chi^{2}=20.91 ; P<0.001\right)$.
} 

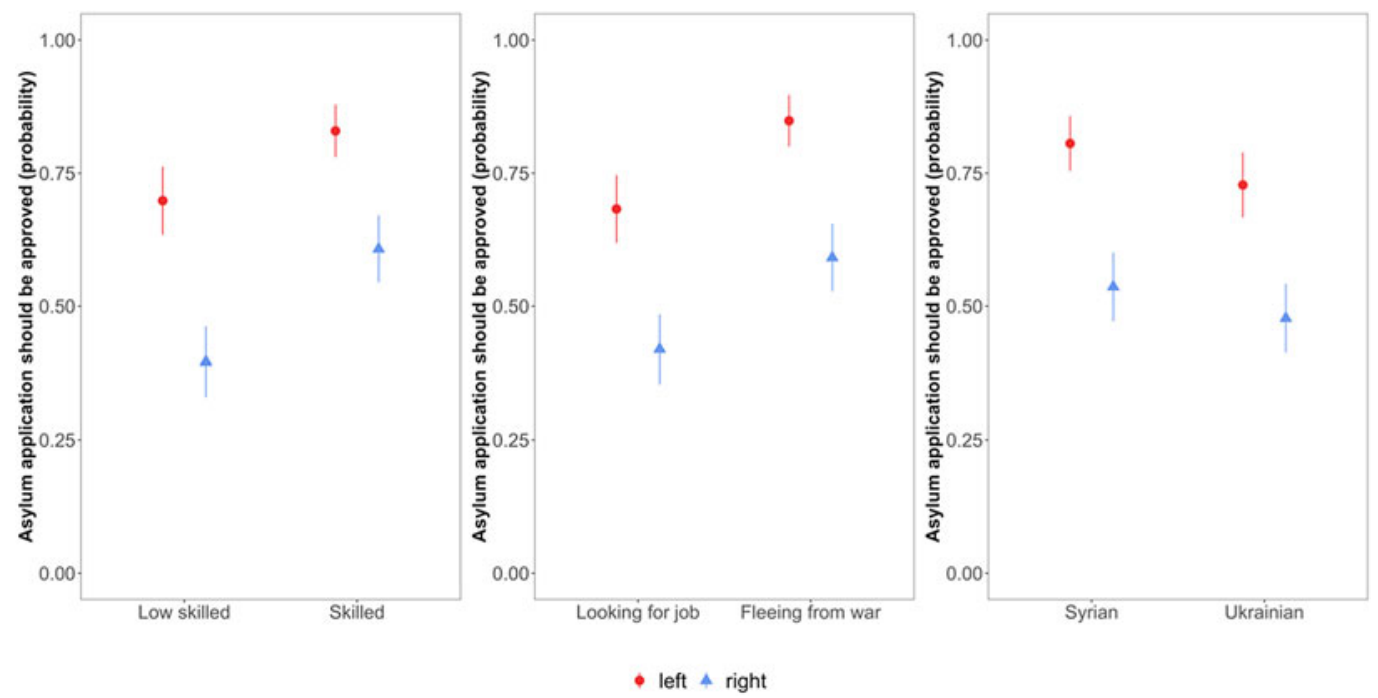

Figure 4. The effect of skills and reasons for leaving the country on the probability to accept asylum applications by respondent's ideology.

Note: Graph shows predicted probabilities based on logit regression. Lines on both sides of the points represent $95 \%$ confidence intervals.

to the ethnicity of the applicant, in contrast with our last hypothesis (h5c), rightists do not seem to be more sensitive to the Muslim-Christian divide as far as the two selected national groups are concerned. $^{6}$

To sum up, in line with previous studies (Iyengar et al., 2013; Bansak et al., 2016; Valentino et al., 2019), Italians take into account both instrumental and humanitarian motives when asked about specific individual applications for asylum. However, these factors do not seem to interact among each other, neither they do with the migrant's ethnic origins, which, at least in our experiment, turn out being irrelevant. Nor we do find an interaction between ideology and reasons behind approving a hypothetical application for asylum, so future research should be conducted on this link. Last, our results hold to some robustness checks (e.g., removal of speeders, weighting, controlling for possible spill-over effects among experiments in the same survey; see Appendix D).

\section{A conjoint analysis on candidate preference}

Personalisation of politics, that is, the gradual shift in the electorate's attention from political parties and issues to specific candidate features, has been the result of broad underlying social and political processes, including the individualisation of social life, the de-freezing of traditional cleavages and the emergence of parties as campaign organisations in a new media environment (Costa Lobo and Curtice, 2015). These patterns have prompted observational research to look at the role of candidate features to explain voting choices, unravelling the importance of some basic traits, among which: competence (being intelligent and knowledgeable), leadership (being inspiring), integrity (being honest) and empathy (being compassionate and caring) (Pancer et al., 1999).

\footnotetext{
${ }^{6}$ The differences between skilled and unskilled is $13 \%$ for leftists and $21 \%$ for rightists, though the contrast is not statistically significant $\left(\chi^{2}=1.69 ; P=0.19\right)$; the difference between looking for job vs. fleeing from war is $16.6 \%$ for leftists and $17.2 \%$ for rightists $\left(\chi^{2}=0.01 ; P=0.92\right)$; the difference between Syrian vs. Ukrainian fleeing from war is $-0.08 \%$ for leftists and $-0.05 \%$ rightists $\left(\chi^{2}=0.10 ; P=0.76\right)$.
} 
The topic has become even more relevant with the success of (neo-)populist parties and leaders. In the ideal type, populist voters would attribute larger importance to valence issues (e.g., corruption) (Curini, 2018), oppose professional politicians (Akkerman et al., 2014), favour candidates who act as 'delegates' (who care only about the interests of her/his electorate) rather than 'trustees' (who are independent and care about the interests of the nation), and, finally, advocate strong leadership (Caramani, 2017).

However, existing research needs to address some relevant problems. First, standard survey measures are prone to social desirability bias, with respondents likely to score as important all the above-mentioned personality traits. Second, interviewees are usually asked to rate each trait individually and not to evaluate candidate profiles characterised by both more and less positive features. In fact, politicians' profiles are multidimensional in nature and that explains the proliferation of conjoint analysis on candidate preferences (e.g., Teele et al., 2018; Franchino and Zucchini, 2015; for a critical view, see Incerti, 2020).

Still, none of the available studies have analysed extensively the role of personality or valence traits suggested by observational research. ${ }^{7}$ Therefore, one possible conjoint experiment on the topic could explore what personality traits make a politician a good candidate in the eyes of the citizens and whether the importance of these traits vary across subgroups of voters based on their populist attitudes. Drawing on the available theoretical and empirical research, we can develop some expectations.

First, we might expect Italians to rate more favourably candidates who have higher levels of competence than those who have less (h1); who show higher moral integrity than apparently dishonest candidates (h2); who are more compassionate than cold and distant (h3). Second, we anticipate populist attitudes to moderate the importance of some traits on candidate favourability. Specifically, we hypothesise populist citizens to dislike professional politicians more than nonpopulists (h4a). Moreover, as compared to non-populist voters, populists will more likely favour candidates with high moral integrity (h4b), strong leadership (h4c) and acting as delegates (h4d).

\section{Data}

Our data come from a panel survey carried out by the Department of Social, Political and Cognitive Sciences at the University of Siena and collected on a sample of the Italian population aged 14 years or older selected within a probability panel held and managed by GfK Italy. The first wave of the survey $(n=3411)$ was conducted between 6 and 25 May, 2019, right before the last European elections and included the key covariate used in this example, that is, a scale eliciting populist attitudes. The second wave $(n=3179)$ was administered in the post-electoral period, from 28 May to 26 June 2019, and contained both the populist scale and the conjoint experiment. We restrict our analysis to subjects aged 18 years or over at the time of the interview $(n=3096)$. When conducting sub-group analysis on populism, we primarily use the populist scale included in the second wave, conducting some robustness tests with the first-wave measure and concentrating on the adult respondents who participated in both waves. Since we have a probability sample resembling the general population on several socio-demographic features albeit more skewed towards the highly educated (see Appendix C) - we have decided to run models on weighted data.

\section{Vignette}

To minimise the effect of response fatigue on the quality of our experimental data and eliminate potential spill-over effects, the conjoint experiment was embedded at the beginning of the questionnaire after a few introductory questions. This is a forced, paired-choice, fully randomised

\footnotetext{
${ }^{7}$ For a factorial experiment on candidate favourability in Italy, see Iyengar and Barisione (2015).
} 
conjoint with discrete and rating choices. Respondents began the experiment by reading a short introduction in which they were invited to reflect about 'the characteristics a candidate should have to enter politics at the European level', and then informed that they would have been provided 'with several pieces of information about people who might have run for the European elections'. Then, for each pair of hypothetical politicians, participants were asked 'which of the two candidates would you personally have preferred to win a seat in the European Parliament'. The experiment builds on the one proposed by Hainmueller et al. (2013). Figure 5 shows one possible conjoint vignette generated through random assignment to the considered macro-traits and relative attributes (for the full stimuli, see Appendix B).

Since respondents had to choose either one or the other candidate, the outcome variable is dichotomous, coming close to a real-world situation in European elections, at least in Italy, in which voters can express a preference among a list of pre-selected candidates. After this choice, participants were also asked to rate each profile on a 7-point favourability scale.

Overall, we manipulated eight macro-traits, implying that our hypotheses are tested in a broad context of candidate features. Moreover, each respondent was exposed to two pairs of candidates, therefore facing the same task twice. Two traits elicited basic sociodemographic characteristics, such as the role of gender and job position. Five traits considered personality features and skills, namely: communication skills, social skills, integrity, competence and leadership. The remaining trait elicited view of role (see Appendix B for the full list of attributes).

Profiles were generated so that the order of macro-traits was randomised and fixed across the two pairings to minimise recency effect and priming. The assignment of attributes, instead, followed an independent fully randomised approach, meaning that all attributes were randomly assigned without restrictions on their possible combination. To check for the correct implementation of the experiment, we first analysed the distribution of considered attributes in the sample - results ensure fair distribution - and then tested for balance in our main covariate (the populist scale) - results suggest that imbalance should not be a matter of concern (see Appendix B).

\section{Empirical analysis}

In our experiment, 2676 respondents rated 10,704 profiles (5352 pairings), with a design yielding 1536 possible profile combinations. In conjoint analysis, as mentioned above, the causal quantity of interest is the average marginal component effect (henceforth AMCE). In our example, this corresponds to the average difference in the probability effect of being preferred for winning a seat in the European Parliament when comparing two different attribute levels - e.g., a candidate with a 'clean criminal record' versus a candidate being 'under investigation' - while keeping all other attributes constant. Since attributes are randomised, profiles with a 'clean criminal record' will have, on average, the same distribution on all other attributes as compared to profiles 'under investigation' (as we positively tested). In the subsequent analysis, the dependent variable will be a dichotomous variable measuring people's choice.

Following Hainmueller et al. (2013), we estimated a linear probability model to assess the role of the different profile traits and the relative assigned attributes on people's candidate choice. In this case, the explanatory variables are a series of dummies for each of the attributes of the macrotraits under consideration. Since each participant carried out two different tasks, observations are not independent, so we clustered standard errors by respondent. As said, AMCE conveys information on the marginal causal effect of an attribute against a reference category. Following Leeper et al. (2019), we also computed unadjusted marginal means (henceforth MM) to give a more detailed description of the respondents' preference for all feature levels. Again, we will only show graphical results to ease interpretation (see Appendix D for full models).

Which of the considered traits does meet the favourability of the respondents, increasing the probability of choosing a certain candidate? Figure 6 shows the AMCE of each attribute against the baseline, so that when the point estimate and confidence intervals cross the zero line, the 


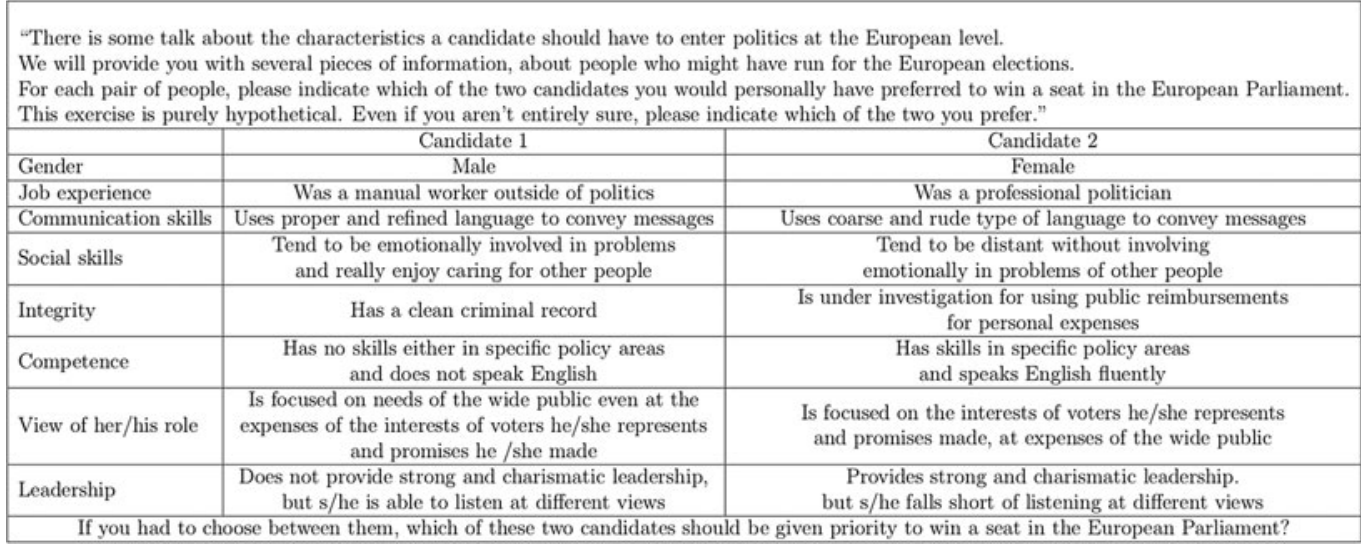

Figure 5. Stimuli: an illustration of the conjoint experiment.



Figure 6. Average marginal component effect: effects of candidate traits on preference for election.

Note: Lines on both sides of the points represent $95 \%$ confidence intervals. The points without horizontal bars denote the attribute value used as a reference category.

attribute has no effect. When the coefficient leans towards the right, taking positive values, it produces a positive change in the probability of choosing a certain candidate. On the contrary, when the coefficient leans towards the left, taking negative values, it yields a negative change in the probability. As can be seen, being a woman does not exert an effect compared to being a man. Conversely, many job positions outside politics - manual worker $(+6 \%, P<0.01)$, engineer ( $+5 \%, P<0.01)$, university professor $(+4 \%, P<0.01)$ - increase the probability of being chosen if compared with a professional politician. This would confirm a negative bias towards a longterm political career. 
Considering the way a candidate might conceive her/his role, being a trustee, who is focused on the national interest, seems to be favoured over a candidate who interprets the role as a delegate focused on the mere interest of her/his voters $(+3 \%, P<0.01)$. Similarly, a candidate who favours collegiality is preferred over a strong leader $(+4 \%, P<0.01)$, and, reasonably, proper and refined communication skills exert a positive effect on candidate selection $(+8 \%, P<0.001)$.

Coming to the traits on which our attention is focused, competence increases the probability of being favoured as compared to less expertise in specific policies or fluency in English $(+6 \%$, $P<0.001)$. Moreover, caring about the problems of other people and being emotionally involved exert a positive effect on candidate selection as compared to the baseline category for this trait $(+4 \%, P<0.01)$. Still, the most important trait by far is integrity, with candidates showing a clean criminal record being supported much more than those under investigation. The increase in probability is equal to 22 percentage points, a strong and statistically significant effect $(P<0.001)$. Overall, our first three expectations (h1, h2, h3) are corroborated, albeit with differences in the magnitude of effects. All these conclusions are largely substantiated by MM results (see Appendix D).

Now, are these results conditioned by individuals' populist attitudes? To evaluate this, we first need to distinguish our respondents according to their level of populism. To do this, we rely on a scale developed by Akkerman et al. (2014) and derived from a six-item battery aimed at capturing a latent attitudinal dimension characterised by three main aspects: people-centrism, anti-elitism and Manichaeism. We tested it via factor analysis and computed factor scores to get a synthetic measure of populism (full results are reported in Appendix D). Then, we ran separate models for respondents who were either above or below the median value of the resulting populist score to gauge whether the effect of attributes changed according to their level of populism.

Figure 7 summarises the results in three panels. Moving from left to right, it displays the AMCEs of attributes when populism is high, low and the difference between the two, thus allowing to detect any subgroup difference. The first thing we can notice is that, if compared with nonpopulist respondents, populists seem to favour candidates with some job experience (especially farmers, manual workers) over professional politicians. Looking at MMs (Appendix D), however, this is not the product of a strong preference for working-class positions or manual jobs, but of a general disapproval of professional politicians. Specifically, populists tend to punish this type of candidates $7 \%$ more than non-populists $(P<0.01)$, confirming our hypothesis $(\mathrm{h} 4 \mathrm{a})$. Moreover, populists appear to be more sensitive to moral integrity, with a $7 \%$ increase in the probability of choosing a candidate with a clean criminal record over a candidate under investigation, compared to non-populists. Therefore, also in this case, our expectation is corroborated (h4b). On the other hand, against popular accounts ( $\mathrm{h} 4 \mathrm{c}$ and $\mathrm{h} 4 \mathrm{~d}$ ), we do not find populists to prefer strong leaders or candidates who act as delegates.

We might conclude that citizens take into account personality traits eliciting valence features when evaluating candidate fit for elections. These have to do with communication and social skills, view of the role and leadership. There is an opposition towards professional politicians and, in line with previous research (Franchino and Zucchini, 2015), moral integrity is by far the most important aspect, with both results more pronounced in the case of populist respondents. A series of robustness checks confirm the reliability of our results (i.e., changing the way we measure the dependent variable, removing subjects depending on their level of attention during the survey, performing sub-group analysis using a measure of populism from the first survey wave, handling randomisation problems; see Appendix D).

\section{Conclusions}

The experimental approach constitutes the prime method in the quest for causality. Nowadays, political scientists willing to embark in experimental research may take advantage of a growing number of studies and choose the strategy that best fits their objectives among a wide menu of designs and settings. Of course, none of these options is free of limitation, so that doing 


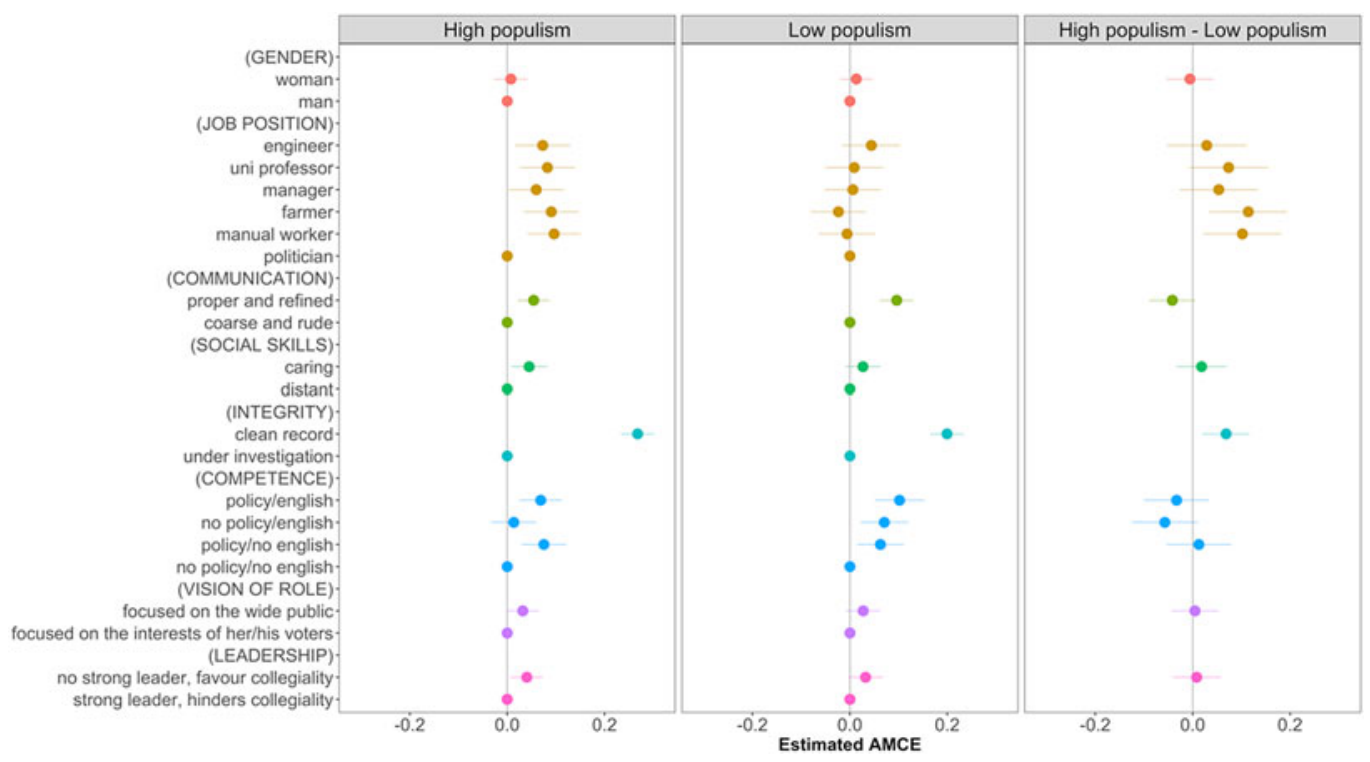

Figure 7. Average marginal component effect for populists and non-populists.

Note: Lines on both sides of the points represent $95 \%$ confidence intervals. The points without horizontal bars denote the attribute value used as a reference category.

experiments needs a good deal of creativity together with a deep awareness of the potential tradeoffs between the control of the experimental setting and the external validity of the results.

This article has tried to give an overview of the basic concepts underneath the experimental method, highlighting the amount of scholarly interest in the field and possible designs to use. It has addressed the main differences among various experimental settings and discussed the main applications and potential problems in the use of survey experiments in particular. When combining randomised assignment and representative samples, survey experiments allow the researcher to make population inferences about causal relationships between variables of interest. Yet, survey experiments are not necessarily the final remedy for the study of causality and researchers should problematise each single step in their design, planning and implementation. For practical guidance, we have presented the full protocol for a traditional factorial design on individuals' attitudes towards migrants and a more innovative conjoint experiment on candidate preferences, including a set of research questions, the experimental stimuli used to address them, and the way to analyse experimental data.

The exposure and acquaintance of political scientists to experimental methods have gradually fuelled experimental publications, with a rapid spread in the number and influence of these manuscripts in the last few decades. We hope that this study, besides offering a general overview on the merit, success and use of experimental designs in international scholarly literature, will contribute to stimulate an increasing interest and usage of the experimental method among the Italian political science community. Bearing in mind the limitations that we have outlined, we can now take advantage of the possibility of experimentation in political research and shook off the idea that the study of politics is only an observational science.

Supplementary material. The supplementary material for this article can be found at https://doi.org/10.1017/ipo.2021.20

Funding. This research received financial support from the project 'Bridging the gap between public opinion and European leadership: Engaging a dialogue on the future path of Europe EUENGAGE' (H2020-EURO-2014-2015/ H2020-EURO-SOCIETY-2014, Grant no. 649281) funded by the European Union's Horizon 2020 research and innovation 
programme (www.euengage.eu) and the Department of Excellence 2018-2022 (2272-2018-IA-PROFCMIUR001) (https:// interdispoc.unisi.it/en/). No conflict of interest.

Data. The replication dataset is available at http://thedata.harvard.edu/dvn/dv/ipsr-risp

Acknowledgments. We thank James N. Druckman for having shared with us the list of experimental articles published by the American Political Science Review over the last six decades and for his encouragement and support in our comparative project on experimental research in Europe and the United States. We also thank Mattia Guidi and Thomas Leeper for their feedback on the analysis. Usual disclaimers apply.

\section{References}

Akkerman A, Mudde C and Zaslove A (2014) How populist are the people? Measuring populist attitudes in voters. Comparative Political Studies 47, 1324-1353.

Alves WM and Rossi PH (1978) Who should get what? Fairness judgments of the distribution of earnings. American Journal of Sociology 84, 541-564.

Bansak K, Hainmueller J and Hangartner D (2016) How economic, humanitarian, and religious concerns shape European attitudes toward asylum seekers. Science (New York, N.Y.) 354, 217-222.

Bansak K, Hainmueller J, Hopkins D and Yamamoto T (2018) The number of choice tasks and survey satisficing in conjoint experiments. Political Analysis 26, 112-119.

Bansak K, Hainmueller J, Hopkins D and Yamamoto T (2021) Beyond the breaking point? Survey satisficing in conjoint experiments. Political Science Research and Methods 9, 53-71. https://doi.org/10.1017/psrm.2019.13.

Barabas J and Jerit J (2010) Are survey experiments externally valid? American Political Science Review 104, $226-242$.

Barisione M (2020) When ethnic prejudice is political: an experiment in beliefs and hostility toward immigrant out-groups in Italy. Italian Political Science Review/Rivista Italiana Di Scienza Politica 50, 213-234.

Basile L and Olmastroni F (2020) Sharing the burden in a free riders' land: the EU migration and asylum policy in the views of public opinion and politicians. European Journal of Political Research 59, 669-691.

Berinsky AJ, Margolis MF and Sances MW (2014) Separating the shirkers from the workers? Making sure respondents pay attention on self-administered surveys. American Journal of Political Science 58, 739-753.

Caramani D (2017) Will vs. reason: the populist and technocratic forms of political representation and their critique to party government. American Political Science Review 111, 54-67.

Charness G, Gneezy U and Kuhnc MA (2012) Experimental methods: between-subject and within-subject design. Journal of Economic Behavior \& Organization 81, 1-8.

Coppock A, Leeper TJ and Mullinix KJ (2018) Generalizability of heterogeneous treatment effect estimates across samples. Proceedings of the National Academy of Sciences 115, 12441-12446.

Costa Lobo M and Curtice J (eds) (2015) Personality Politics? The Role of Leader Evaluations in Democratic Elections. Oxford: Oxford University Press.

Curini L (2018) Corruption, Ideology and Populism. The Rise of Valence Political Campaign. Cham: Palgram McMillan.

Druckman JN, Green DP, Kuklinski JH and Lupia A (2006) The growth and development of experimental research in political science. American Political Science Review 100, 627-635.

Druckman JN, Green DP, Kuklinski JH and Lupia A (2011) Experimentation in political science. In Druckman JN, Green DP, Kuklinski JH and Lupia A (eds), Cambridge Handbook of Experimental Political Science. New York, NY: Cambridge University Press, pp. 3-11.

Dunning T (2012) Natural Experiments in the Social Sciences: A Design-Based Approach. New York, NY: Cambridge University Press.

Dunning T and Rosenblatt F (2016) Transparency and reproducibility in multi-method research. Revista de Ciencia Politica 36, 773-783.

Franchino F and Zucchini F (2015) Voting in a multi-dimensional space: a conjoint analysis employing valence and ideology attributes of candidates. Political Science Research and Methods 3, 221-241.

Gaines B, Kuklinski J and Quirk P (2007) The logic of the survey experiment reexamined. Political Analysis 15, 1-20.

Gerber AS and Green DP (2012) Field Experiments: Design, Analysis, and Interpretation. New York, NY: Norton.

Gerber AS, Arceneaux K, Boudreau C, Dowling C, Hillygus S, Palfrey T, Biggers DR and Hendry DJ (2014) Reporting guidelines for experimental research: a report from the experimental research section standards committee. Journal of Experimental Political Science 1, 81-98.

Green DP (2004) Experimental design. In Lewis-Beck MS, Bryman A and Futing Liao T (eds), The SAGE Encyclopedia of Social Science Research Methods. Thousand Oaks, CA: Sage, pp. 354-356.

Green DP and Gerber AS (2003) The under-provision of experiments in political and social science. Annals of the American Academy of Political and Social Science 589, 94-112. 
Guidi M and Martini S (2019) Il Successo della Lega e la Sconfitta dei 5 Stelle: Il Voto Degli Italiani Alle Elezioni Europee 2019. Second DISPOC Interdisciplinary Workshop, Siena, September 26. https://bit.ly/3e09iYY

Hainmueller J, Hopkins D and Yamamoto T (2013) Causal inference in conjoint analysis: understanding multidimensional choices via stated preference experiments. Political Analysis 22, 1-30.

Hainmueller J, Hangartner D and Yamamoto T (2015) Do survey experiments capture real-world behavior? Proceedings of the National Academy of Sciences 112, 2395-2400.

Incerti T (2020) Corruption information and vote share: a meta-analysis and lessons for experimental design. American Political Science Review 114, 761-774.

ISTAT (2017) Movimento e Calcolo Della Popolazione Straniera Residente e Struttura per Cittadinanza. Available at http:// siqual.istat.it/SIQual/visualizza.do?id=0019700\&refresh=true\&language =IT

Iyengar S (2011) Laboratory experiments in political science. In Druckman JN, Green DP, Kuklinski JH and Lupia A (eds), Cambridge Handbook of Experimental Political Science. New York, NY: Cambridge University Press, pp. 73-88.

Iyengar S and Barisione M (2015) Non-verbal cues as a test of gender and race bias in politics: the Italian case. Italian Political Science Review/Rivista Italiana Di Scienza Politica 45, 131-157.

Iyengar S, Jackman S, Messing S, Valentino NA, Aalberg T, Duch R, Hahn KS, Soroka S, Harell A and Kobayashi T (2013) Do attitudes about immigration predict willingness to admit individual immigrants? A cross-national test of the person-positivity bias. Public Opinion Quarterly 77, 641-665.

Kinder DR and Sanders LM (1996) Divided by Color: Racial Politics and Democratic Ideals. Chicago, IL: University of Chicago Press.

Leeper TJ, Hobolt S and Tilley J (2019) Measuring subgroup preferences in conjoint ex- periments. Political Analysis 28, 207-221.

Ma DS, Correll J and Wittenbrink B (2015) The Chicago face database: a free stimulus set of faces and norming data. Behavior. Research Methods 47, 1122-1135.

McDermott R (2011) Internal and external validity. In Druckman JN, Green DP, Kuklinski JH and Lupia A (eds), Cambridge Handbook of Experimental Political Science. New York, NY: Cambridge University Press, pp. 27-40.

McGraw KM and Hoekstra V (1994) Experimentation in political science: Historical trends and future directions. In Delli Carpini MX, Huddy L and Shapiro RY (eds) Research in Micropolitics: New Directions in Political Psychology. Greenwich, CT: JAI Press, pp. 3-29.

Morton RB and Williams KC (2010) Experimental Political Science and the Study of Causality: From Nature to the Lab. Cambridge: Cambridge University Press.

Mullinix KJ, Leeper TJ, Druckman JN and Freese J (2015) The generalizability of survey experiments. Journal of Experimental Political Science 2, 109-138.

Mutz D (2011) Population-Based Survey Experiments. Princeton: Princeton University Press.

Mutz D and Pemantle R (2015) Standards for experimental research: encouraging a better understanding of experimental methods. Journal of Experimental Political Science 2, 192-215.

Pancer S, Brown S and Barr C (1999) Forming impressions of political leaders: a cross-national comparison. Political Psychology 20, 345-368.

Rugg D (1941) Experiments in wording questions: II. Public Opinion Quarterly 5, 91-92.

Sniderman PM (2018) Some advances in the design of survey experiments. Annual Review of Political Science 21, $259-275$.

Sniderman PM and Grob DB (1996) Innovations in experimental design in attitude surveys. Annual Review of Sociology 22, 377-399.

Teele DL, Kalla J and Rosenbluth F (2018) The ties that double bind: social roles and women's underrepresentation in politics. American Political Science Review 113, 525-541.

Transue J, Lee D and Aldrich J (2009) Treatment spillover effects across survey experiments. Political Analysis 17, $143-161$.

Valentino NA, Soroka SN, Iyengar S, Aalberg T, Duch R, Fraile M, Hahn KS, Hansen KM, Harell A, Helbling M, Jackman SD and Kobayashi T (2019) Economic and cultural drivers of immigrant support worldwide. British Journal of Political Science 49, 1-26.

Zizzo DJ (2010) Experimenter demand effects in economic experiments. Experimental Economics 13, 75-98.

Cite this article: Martini S, Olmastroni F (2021). From the lab to the poll: The use of survey experiments in political research. Italian Political Science Review/Rivista Italiana di Scienza Politica 51, 231-249. https://doi.org/10.1017/ipo.2021.20 